\title{
Íntimos e históricos: los títulos de La otra sentimentalidad
}

\author{
Miguel Ángel GarCíA \\ Universidad de Granada
}

\begin{abstract}
Contra la creencia en un sujeto expresivo atemporal, los poetas de La otra sentimentalidad partieron de la premisa de que el yo y la intimidad son una construcción histórica. A la vez, entendieron lo público y lo colectivo como correlato de lo privado y lo individual. De acuerdo con una práctica teórica marxista que subrayaba la radical historicidad de la literatura y la definía como producción ideológica, trataron de cuestionar en su práctica poética la norma literaria establecida. Este artículo procura contextualizar los títulos de sus libros y poemas.
\end{abstract}

Keywords: poesía española contemporánea, La otra sentimentalidad, títulos, intimidad, historia

\section{Manifiestos y práctica teórica}

La otra sentimentalidad se vio empujada a combinar inicialmente práctica poética y práctica teórica. Hablar de la poesía y de la teoría literaria o de la teoría en general como «prácticas» es marcar los términos en un sentido muy determinado, en el sentido en que Althusser, uno de los referentes básicos de este movimiento granadino siempre a partir de la figura tutelar del profesor Juan Carlos Rodríguez, pensó la filosofía como teoría de la práctica teórica o, sin duda de forma mucho más decisiva, como lucha de clases en la teoría, en el nivel ideológico. Los jóvenes poetas y universitarios Álvaro Salvador y Luis García Montero trataban de teorizar sobre «una sentimentalidad otra» -el galicismo sintáctico tenía importancia para su maestro Rodríguez- en el célebre manifiesto conjunto de 1983, aunque ya habían adelantado sus respectivas posiciones en la prensa. Menos académico, más puro poeta, que no poeta puro, Javier Egea también intentaba manifestarse con una «Poética» que incidía en la noción de complicidad -cuatro años despúes vendría un título como Diario cómplice, de García Montero-invirtiendo precisamente al Juan Ramón Jiménez del conocido poema «Vino, primero, pura». En este caso, la poesía vino para los jóvenes granadinos primero «frívola» (¿los novísimos, la resaca esteticista y culturalista?) y, antes de visitarles con extraños abrigos y de que luego se desnudase y le sonrieran, quisieron su cuerpo sobre las escombreras para que «también manchase» su ropa en la tardanza de luz y libertad (Egea, Salvador y García Montero I983: 25).

Manchar la ropa o el traje de la poesía, como pedía Neruda en su no menos célebre manifiesto de 1935, quizás no era la imagen más apropiada 
porque se trataba, al menos en el plano de la práctica teórica, de dejar atrás las viejas dicotomías de la ideología burguesa pureza/impureza, belleza/ compromiso o poesía/historia, así como sus correlativas privado/público y sentimiento/razón. Tampoco era muy acertada la idea de llevar la poesía «por las calles», aunque la imagen entroncase directamente con la que emplearon en algún momento Alberti, Otero o Ángel González (Martín Gijón 20I6: 77) y aunque todo esto supusiera en efecto, como escribe Egea en este poema extraordinario, en cualquier caso impecable desde el punto de vista de la práctica poética, una «tierna venganza» contra la ideología literaria dominante, que sitúa la poesía en el ámbito de lo trascendental, de lo puro y lo privado. No era simplemente cuestión de manchar la poesía o de volverla impura, haciendo que bajase a la calle. Eso ya se había intentado y no había supuesto romper con las reglas de juego trazadas por la ideología burguesa o pequeñoburguesa de lo poético y sus mencionadas dicotomías, con la «mitología tradicional del género» a la que se refería en ese texto de 1983 García Montero. Sobre todo era cuestión, al menos para la Poética personal del maestro Juan Carlos Rodríguez, la que años más tarde sistematizaría en un libro indispensable sobre La otra sentimentalidad (Jauralde Pou 2000: I46), de pensar las cosas de otro modo, de llevarlas a otro terreno, siempre sin negar ni esconder «la palabra maldita: el marxismo» (Rodríguez I999: 25). Un marxismo ante todo althusseriano (si bien con ciertas aperturas al psicoanálisis, al freudiano más que al lacaniano) que impulsaba a teorizar la necesidad de escribir arrancando no ya de lo colectivo (se estaba lejos de cualquier asomo de realismo socialista, esa consigna en materia estética del estalinismo, tan detestado como el capitalismo) sino de la propia subjetividad, pero no concibiéndola como un principio absoluto sino poniéndola en duda por estar «construida y podrida» (26) por el inconsciente ideológico (aquí la articulación de Marx y Freud) derivado de las relaciones sociales capitalistas, las cuales a su vez derivan de unas relaciones de producción y de explotación históricamente muy concretas.

El manifiesto de García Montero dialogaba con los planteamientos teóricos del profesor Rodríguez sobre la subjetividad burguesa, sobre la lógica del sujeto libre como fundamento de la literatura tal y como la entendemos hoy, lo cual le había llevado en su seminal Teoría e historia de la producción ideológica (1974) a postular que la literatura no ha existido siempre, esto es, a hacer hincapié en la radical historicidad de la literatura y a definirla como un discurso ideológico. En concreto, García Montero corregía al Bécquer para quien «Poesía eres tú» señalando que para la ideología literaria hegemónica «Poesía soy yo» (la poesía como «expresión literal de las esencias más ocultas del sujeto») y alertaba de cómo el «yo sensible, cimiento de la moral burguesa», se sirve de la poesía para reproducirse. Más abiertamente, la práctica teórica de Rodríguez subrayaba que la ideología burguesa 
nos interpela y construye, nos individualiza históricamente como sujetos libres para así explotarnos. Si la poesía logra olvidar el fantasma de los sentimientos propios, argumentaba García Montero, puede convertirse en un instrumento objetivo para analizarlos y para «construir una sentimentalidad distinta, libre de prejuicios, exterior a la disciplina burguesa de la vida». Por su parte, Salvador se apoyaba en Machado/Mairena para postular que los sentimientos son algo históricamente fechado, el producto de un determinado horizonte ideológico. Para poder hablar de otra sentimentalidad, añadía, no solo había que entender la vida y sus relaciones de otra manera, sino vivirlas también de otra manera. Juan Carlos Rodríguez había enseñado a estos jóvenes que la poesía podía y aun debía ser una forma de vida, otra forma de vida, pero de vida cotidiana, al margen de cualquier vitalismo poético maldito, bohemio o esteticista del pasado. No obstante, al situarse precisamente en la otra orilla del marxismo, al propugnar una «escritura ideológica e inmanente o materialista» (Rodríguez I999: 40), no solo discutía los conceptos kantianos de nueva u otra «sensibilidad» (4I-42), que podían llevar a la confusión y a echarlo todo a perder, sino también el machadiano -en el fondo pequeñoburgués- de «nueva sentimentalidad», por mucho que Mairena acariciase la historicidad de los sentimientos, la construcción histórica de la intimidad, al definirlos como resonancias cordiales de los valores en boga y sostener que cambian en el curso de la historia y aun durante la vida individual del hombre.

Próximo a la práctica teórica marxista inequívoca que amparó a La otra sentimentalidad, pero no tan próximo a su práctica poética, ni siquiera a la práctica teórica de sus poetas, Trotski plantea, al críticar el inmanentismo purista del formalismo ruso, que un poeta usa el lenguaje para desempeñar tareas fuera de este y que ello es cierto incluso cuando limita su campo «a la lírica, a su amor y a su muerte personal». A partir de aquí sostiene que las formas sociales del amor, aunque no así la base sexual del hombre, cambian rápidamente. Estas formas afectan a «la superestructura psíquica del amor» y significan nuevas exigencias en el terreno poético. El poeta no puede encontrar materiales para la escritura más que en su medio social. Sentimientos y pensamientos nuevos buscan abrirse paso «a través de la corteza oscura del subconsciente» y alcanzar formulación poética: «Si no hubiese cambios psíquicos producidos por los cambios en el medio social no habría movimiento en el arte: de generación en generación, la gente seguiría contentándose con la poesía de la Biblia o de los griegos antiguos» (Trotski I973: 87). ¿No dice Trotski lo mismo que Machado, pero de otra manera? Aquí por ejemplo, en la teoría marxista quiero decir, y no ya solo en Trotski, estaba aovillada la historicidad de los sentimientos (para empezar, el sentimiento del amor), como la historicidad de todo, pero había que saber extraerla, producirla asimismo. La radical historicidad de la literatura y la literatura como 
discurso o producción ideológica son, al fin al cabo, los dos presupuestos teóricos de los que habría que partir para entender hasta sus últimas implicaciones el título de ese manifiesto fundacional, La otra sentimentalidad, un concepto presente en los títulos de los manifiestos individuales de García Montero, primero, y Salvador, después, aunque Juan Carlos Rodríguez, alentador de una práctica poética inmanente y materialista, juzgase con el tiempo que ya en ese libro de 1983 había comenzado a desvanecerse el movimiento en su sentido originario (Rodríguez 1999: 4I; Salvador 20I7a: 244). Quizás, pese a las fecundas confluencias, su práctica teórica fuerte fue por un lado y la práctica poética, incluso la práctica teórica de los poetas, fue por otro.

El caso es que, si se llegaba a la conclusión de que solo se podía escribir a partir de una individualidad construida por un inconsciente ideológico y un inconsciente libidinal anteriores a ella (Rodríguez 1999: 39), si Marx y Althusser habían enseñado a ver los individuos como soportes de relaciones sociales inconscientes, el sujeto poético solo podía ser una ficción y el poema «el escenario donde esta ficción se desarrollaba» (48-49). Se sabe que García Montero entendía en su manifiesto de 1983 el poema como una puesta en escena, como un pequeño teatro, hasta el punto de sentenciar que «solo cuando uno descubre que la poesía es mentira -en el sentido más teatral del término- puede empezar a escribirla de verdad» (Egea, Salvador y García Montero 1983: I4). No son separables, como observa Díaz de Castro (2003: 25), la cuestión de la ficcionalidad poética (Wahnón 2003) y la concepción de la poesía como producción ideológica radicalmente histórica. La ficcionalización del yo a la que llega La otra sentimentalidad, compartida con la poesía de la experiencia (Simonet León 20I7), era una forma de cuestionarse la subjetividad burguesa, el esencialismo del sujeto lírico expresivo. Se tenía conciencia de la historicidad del yo, de que la intimidad se construye en la historia. Desde la práctica teórica fuerte se dejaba ver que la privacidad no existía al margen de lo público, que era su correlato obligatorio (Rodríguez I999: 29). Poco después, como ha recordado Lanz (2018: I48) en un panorama exhaustivo, García Montero hablaría de un realismo singular, argumentando que la historia solo se vive en primera persona y que en consecuencia, abatidas las fronteras entre lo privado y lo público, resulta conveniente llegar a una definición histórica de la propia intimidad, concebirla como un territorio histórico e ideológico, al modo en que lo hizo Alberti en ciertos poemas de su libro De un momento a otro, a la vez íntimos e históricos, muy en la línea de lo buscado por La otra sentimentalidad (Iravedra 2007: 23-24), y desde luego al modo en que lo hicieron poetas del 50 como Gil de Biedma y Ángel González (Martín Gijón 2016: 69-70).

Si la poesía se consideraba mentira, no era solo porque un yo construido por su inconsciente ideológico y por la historia hiciese de ella un teatro 
representando un personaje en lugar de expresarse o desnudar su supuesta verdad interior (Alonso Valero 20I0: 204), sino a la vez porque se pensaba como un artefacto. Según planteaba Juan Carlos Rodríguez en el cuaderno de poemas País de amor (I989), el verdadero compromiso de la poesía consiste en ser la producción de un artificio o un arte, no una esencia previa sino una producción histórica: «Podemos empezar a hacer otra historia, aunque solo sea partiendo de la base del hacer de la poesía» (Rodríguez I999: 88; Martín Gijón 20i6: 65). Esta era la auténtica toma de partido de la poesía: la contradicción con la ideología dominante, la transformación del inconsciente ideológico que nos conforma y nos explota incluso en nombre de la libertad. La otra sentimentalidad suponía o al menos debió suponer un sí a la poesía desde la historia (Aparicio Durán 20I6) que a la vez era un no a la explotación. No se trataba de comprometer políticamente la poesía sino, como señaló García Montero con agudeza, de poner la poesía en un compromiso (Salvador 1994: 47; García 2002). Lo único que hacía la dialéctica pureza/compromiso era soslayar el verdadero vínculo entre historia y literatura (Roso I993: 27-3I). El compromiso del poeta no residía en su postura civil, era un acto de escritura (Lanz 20I8: I32), pero entendiendo por escritura algo muy distinto de lo que entendía Barthes, incluso el Sartre teorizador del engagement al que respondía Barthes, solo atento a la «moral de la forma». Esto es, entendiendo por escritura una práctica materialista e inmanente, una «escritura del cuerpo» (Rodríguez 1999: 43-44), por historia el objeto teórico construido desde el marxismo y por literatura un discurso ideológico, producido en el nivel de la ideología y con efectos en él.

Qué duda cabe de que el mejor título que pudieron encontrar estos jóvenes poetas granadinos, que desde luego también desplegaron sus estrategias para incidir en el campo literario del momento (Bellón Aguilera 2007: 803), fue ese de La otra sentimentalidad. En el mismo año de I983 Juan Carlos Rodríguez lo defendió, convirtiendo la presentación de El jardín extranjero en «casi un manifiesto» sobre La otra sentimentalidad, como él mismo subtituló este texto. En él exponía que la de García Montero era una poesía que decía cosas, pero «de otra manera», desde la otra orilla, como indicaba Brecht, y que lo hacía en un momento en que la ideología burguesa, en tanto que triunfadora por todas partes, ya no necesitaba decirse, tan solo que se la viviese inconscientemente. No había, en principio, nada que decir porque el capitalismo se había impuesto como «forma única de vida» (Rodríguez I999: I72). Justamente esto es lo que habría venido a significar La otra sentimentalidad: un intento de no confundir, después de la lucha antifranquista y la Transición, la democracia como «forma de vida inalienable»-por usar palabras del propio Rodríguez (50) - con el capitalismo y con la Posmodernidad neoliberal, que igualaba engañosamente libertad y libre mercado (Carriedo Castro 2012 y 20I8) o proclamaba el final de la Historia y de las 
ideologías. Sin embargo, frente a ese no decir cosas de la norma poética y de la norma en general, porque todo estaba dicho, frente a ese bavardage -la otra cara de la mudez- o esa infinita expansión y desmesura del lenguaje a las que, de acuerdo con Nancy (2004: 29), resiste la poesía, la de García Montero se afirmaba diciendo cosas, «produciéndose como radical historicidad de la vida» desde la contradicción: «La contradicción se inscribe, pues, en la historia como discurso y en el discurso de la historia, en tanto que otra ideología poética» (Rodríguez 1999: I74). A la luz de estas consideraciones, se comprendía el término «sentimentalidad» como el aire que se respira, como el agua en que se nada, como el inconsciente que nos habita en cada gesto de vida o de escritura, y jamás dentro de la dicotomía kantiana de lo racional y lo sensible: «Si nosotros reivindicamos una otra sentimentalidad, donde incluimos la situación de la contingencia vital, de la historia como realidad de piel, de la tolerancia o la ternura, es sencillamente por el respeto que pedimos para una situación vital habitable, transformable, desde la convicción de que, en efecto, la historia se puede transformar» (175). Había que lograr que las palabras significaran lo otro distinto de la explotación y la violencia inscritas en las relaciones sociales capitalistas; había que convertir la palabra poética y su fuerza inmanente, su materialidad histórica, en un arma afilada para la lucha ideológica, para una lucha de posiciones defensivas que no se podía abandonar (I76-I77). La poesía del autor de El jardín extranjero, concluía Rodríguez, solo podía entenderse como una «práctica ideológica de transformación».

La coherencia con lo que este teórico insobornable había planteado tres años antes, en 1980, a partir de otros dos títulos básicos para el arranque de La otra sentimentalidad, Las cortezas del fruto, de Álvaro Salvador, y Troppo mare, de Javier Egea, era absoluta. En el prólogo al primero de estos libros, resalta la importancia de profesionalizar la poesía en un sentido materialista, de «asumir la práctica poética como un instrumento más de la lucha ideológica», como «forma estricta de producción de ideología». Todo ello bajo la convicción de que «transformar los ritos poéticos supuestamente neutrales en ritos poéticos conscientemente ideológicos equivale a transformar el carácter ahistórico (burgués) de la poesía en su realidad histórica, en su realidad de clase» (Rodríguez 1999: 136). La que venimos llamando práctica teórica fuerte también brilla en la presentación de una lectura poética de Egea, cuyo Troppo mare, que para Juan Carlos Rodríguez marca una ruptura (en el sentido althusseriano de coupure), pues trae un poeta situado en un horizonte materialista, un poeta «otro», se publicará cuatro años después. Aquí postula que la poesía no es la transparencia directa del espíritu del autor, del espíritu humano en general. La poesía no dice las contradicciones de la psicología o el alma de un autor sino las contradicciones y las huellas de un inconsciente ideológico. Constituye entonces una práctica en el te- 
rreno de la ideología, del inconsciente cotidiano. El autor de Troppo mare habría dejado atrás el rito y el mito de la palabra poética y habría comenzado a entender la poesía como práctica ideológica. No se movería ya en la ideología de la palabra poética (creación, expresión) sino en «la conciencia de que la palabra no es nunca inocente, que la poesía es siempre ideológica, que la ideología es siempre inconsciente y que el inconsciente no hace otra cosa que trabajarnos y producirnos como explotación y como muerte» (I56). El inconsciente ideológico capitalista, claro está. El desafío estaba tendido otra vez hacia los poetas: «Hay solo el lenguaje podrido de la explotación ideológica que tenemos que transformar para producir otra práctica de la poesía» (I56).

\section{Títulos y práctica poética}

Insisto en que esta era la práctica teórica fuerte, el humus donde supuestamente se asentaba la práctica poética, incluso la práctica teórico-poética, de La otra sentimentalidad. Y me temo que solo desde estas tres prácticas podemos explicarnos los títulos que estos jóvenes granadinos dieron a sus libros y poemas, y para empezar a su movimiento poético, como antes he señalado. Parece claro que los ya citados Las cortezas del fruto (I980), Troppo mare (1984) y El jardín extranjero (I983) son libros fundacionales de la corriente. Por distintas razones tomaré en cuenta, sin embargo, otros títulos que les precedieron y otros que les siguieron y que aún parecían cobijarse bajo el rótulo de La otra sentimentalidad y no bajo el cada vez más pujante de poesía de la experiencia. Aclaro que en esta ocasión solo me centraré en el núcleo duro del grupo, en los tres poetas que integraron el manifiesto de I983.

Para empezar, interesa La mala crianza (I974), de Álvaro Salvador, porque su autor invoca en un sustancioso prólogo a Althusser y a Freud y precisa que la poesía es un tipo de producción ideológica y el poeta un productor (Salvador 1978: 8). El poema que da título al libro juega a la intertextualidad con el Gil de Biedma de «Infancia y confesiones»: «Nosotros los nacidos en el año cincuenta / además de partir / el siglo en dos mitades, / además de nacer sin pérgola / y con tenis (perdonadnos a medias), / sencillamente fuimos / mal criados con saña» (I3). Salvador y García Montero publicaron Tristia en 1982 bajo la identidad compartida de Álvaro Montero, nombre de uno y apellido de otro (Miró I983: 6). El título del libro, que coincide con el de la tercera parte, es un guiño al de Ovidio, quien desterrado por Augusto a un poblado perdido del Mar Negro, como explica una cita liminar de Robert Graves, escribe sus poemas de tristeza. La primera parte lleva el título de «Diario de Firenze». En 1989 García Montero publicó sus poemas de Tristia junto a El jardín extranjero. En 2017 Salvador ha hecho lo propio empleando el título de esa primera parte. Naturalmente, ciertos poemas se ambientan 
en Florencia, como «Los oficios», que remite a la Galería de los Uffizi, y «Ponte Vecchio", inspirado en el encuentro de Dante con Beatriz; otros siguen esa atmósfera italianizante, como «Siesta en Villa Médici», y no faltan los que tratan de Granada, como «De un caminante extranjero que reflexiona sobre el destino de su patria»o «Los encuentros» (¿un eco del mismo título aleixandrino?), que recrea la entrevista de Navagero y Boscán en los jardines de la Alhambra. La inevitable presencia lorquiana (Miró I983: 6), del Lorca del Diván, se deja ver en dos títulos, «Muwassaha del amor que se fue y no vino» $\mathrm{y}$ "Gacela del joven ignorante», que ha sido vista como un buen ejemplo de sentimientos fechados (Romano 2012: 78) y que acaba con estos dos espléndidos versos: «Del Amor nada sé, solo conozco / el cuerpo de mi amada» (Salvador 20I7a: 69).

El título del fundacional Las cortezas del fruto se explica también desde una cita introductoria de Lenin -ni más ni menos- que subraya la necesidad de comprender y descortezar. Dentro de este libro, el poema-prólogo «La práctica poética teórica» revela con claridad el impacto del pensamiento de Juan Carlos Rodríguez. Por si el título no fuera del todo indicativo, el texto termina pidiendo que la poesía sea «instrumento consciente de acción para la historia». La primera sección da título al volumen y además lleva un subtítulo no menos revelador: «Las cortezas del fruto (o la liquidación de la conciencia poética de ayer)». Tanto «La gaya ciencia» como «Sozein ta fainomena» -un título que Salvador toma de unas páginas de Teoría e historia de la producción ideológica - inciden en la mentira de la poesía, uno de los postulados más vistosos, ya lo sabemos, de La otra sentimentalidad. «Desnuda pulpa», la segunda sección, sostiene la imagen nuclear del libro e incluye el poema «Las cortezas del fruto», donde se habla de arrancar «un trozo de corteza / hasta dejar expuesta la carnosa pulpa / del fruto que te ofrecen» (Salvador 1980: 59). El poema titulado «Felicidad y Luis pasean de la mano por un parque de Londres», dedicado a Felicidad Blanc y a Cernuda, parece adelantar los tonos inherentes a la poesía de la experiencia, pero otro como «El león y el rey de Occidente», que se hace eco del paso de Trotski por Cádiz, camino de América, no desmiente el mundo referencial al que quiso agarrarse La otra sentimentalidad.

El libro central con el que Salvador concurre a este movimiento poético granadino es, con todo, El agua de noviembre (1985), introducido por esta significativa cita de Jorge Meneses, el apócrifo machadiano a quien ya había acudido el autor en su manifiesto de 1983: «Una nueva poesía supone una nueva sentimentalidad y esta, a su vez, nuevos valores». Va flanqueda por sendas citas de José Martí y de Brecht, otro nombre invocado por el grupo. Las dos tienen al amor, el sentimiento básico en que también se concentran estos poetas de Granada, como motivo. Bien pudiera ser que el título del volumen arranque del primer poema, «De noviembre a noviembre», que evoca 
el de una conferencia lorquiana («Cómo canta una ciudad de noviembre a noviembre») y comienza con la imagen de la lluvia. «Birthday (Variaciones sobre un tema de Jaime Gil de Biedma)» se construye, efectivamente, sobre «En el nombre de hoy». Si «Esas no volverán» dialoga por su parte con Bécquer ( $Q$ Que su pasión fue un trágico sainete / lo leímos tú y yo en algunos libros»), y si «La soledad sonora» busca el oportuno eco sanjuaniano y juanramoniano, así como «Noche del mes de mayo» el eco otra vez de Gil de Biedma («Noches del mes de junio»), «Qué será, será» se apoya en el título de la famosa canción, pero con aire de tango, una de las aficiones de estos poetas, que participaron en el libro colectivo Granada tango (1982), para el cual Juan Carlos Rodríguez escribió un magnífico ensayo. Precisamente, es el largo poema «Suena una música»-así se titulará una antología del autor editada por primera vez en 1996- el que da la medida de este libro, como decimos central. Al igual que otros poemas emblemáticos del grupo con los que debe ponerse en estrecha relación («Paseo de los tristes», de Egea; «Sonata triste para la luna de Granada», de García Montero), «Suena una música» es el mejor ejemplo de esa porosidad entre intimidad e historia, experiencia personal y experiencia colectiva, que persiguen estos poetas, enmarcándola siempre en un fondo urbano que supone reconocimiento y a la vez extrañeza: «Esta ciudad que miras no es la tuya» (Salvador 1985: 49).

Definido como un libro de transición (Romano 2012: 49), A boca de parir (1976), sin duda un título poco afortunado, contiene ya poemas que abren un conducto directo hacia el posterior Egea otro-sentimental. Un título como «Hacia otro mar» hace pensar en Troppo mare. Otros como «Ciudad del asedio», «Noticia» $\mathrm{y}$ «Contra ti» inician bajo una rebelión contenida el análisis crítico de la ciudad natal que culminará en el citado «Paseo de los tristes». Pero el poeta está más cerca entonces de empeñar la poesía en el compromiso político que en la lucha ideológica. De aquí un título como Argentina 78 (1983). Con su guiño al Mundial de fútbol, se dedica a las madres de la Plaza de Mayo y forma parte de ese género de literatura escrita contra los dictadores. Troppo mare (1984), un libro mítico que precede en fecha de escritura a Paseo de los tristes (1982) y cuyo título se extrae del Pavese de Lavorare stanca, está dedicado en cambio a Juan Carlos Rodríguez y se abre con el verso inicial de Las cenizas de Gramsci: «No es de mayo este aire impuro». El poema de Pasolini fue uno de los textos referenciales para La otra sentimentalidad. Según confesión propia, García Montero (1989: 8) se basa en el verso siguiente al citado para titular El jardín extranjero. Las seis secciones del libro de Egea se titulan «Troppo mare», «Rosetta», «El viajero», «El estrago», «Coram populo»y «Coda». Los poemas (o las partes del poema, si entendemos cada sección como una pieza única) llevan numeración romana. El II de «Coram populo» recuerda al Alberti que dedica en De un momento a otro un poema a sus años de colegio con los jesuitas, poniendo al descubierto, 
como ya se dijo, la construcción histórica e ideológica de su yo, las raíces de su educación sentimental, según la lectura que de esos poemas hacen los jóvenes granadinos: «¿Qué aventura del miedo, qué pizarras vencidas, / qué lenguaje del fondo de los hábitos negros, / qué triste luz aquella?» (Egea 20II: 232). Dentro de «Coda» se incluye el poema «Leer El Capital», un guiño al libro de Althusser y sus discípulos de la Escuela Normal Superior (Lire «Le Capital») que además reúne en forma apretada, hacia su final, los títulos de las secciones precedentes.

Al lector granadino de Egea o al conocedor de Granada no se le escapa que Los tristes es el nombre del célebre paseo que corre junto al río Darro, al pie de la Alhambra. Existen diversas interpretaciones sobre el origen de este nombre, que desde luego debieron estar en la cabeza de Egea al escoger tal título. El libro está dedicado «A Luis García Montero y a todos los que trabajan por ese tiempo diferente». Un amplio número de poemas, breves y sin título, se agrupan en la primera sección, «Renta y diario de amor», introducida con la cita de la rima becqueriana «Voy contra mi interés al confesarlo...». Resulta un detalle significativo porque lo que quiere plantear Egea es la imposibilidad en último extremo del amor en las relaciones sociales capitalistas. Los sentimientos como el amor no escapan a la lógica del mercado, que lo pudre todo: «Quisimos amarnos / tras los muros altos / de un viejo mercado. // No fueron posibles / sino manos grises, / sino labios tristes» (Egea 20II: 26I). La segunda sección, titulada «El largo adiós», como la novela de Chandler (Juan Carlos Rodríguez contagió a estos jóvenes el gusto por la novela negra, bien presente en el primer libro de García Montero, $Y$ ahora ya eres dueño del puente de Brooklyn), contiene poemas como «Sobre el papel» $\mathrm{y}$ «Materialismo eres tú», este último introducido con la pregunta becqueriana «¿Y tú me lo preguntas?». Intentan dibujar una nueva relación con la mujer, lejos de idealizaciones, viéndola ahora como compañera en la dura experiencia de la explotación, la soledad y la derrota, y a la vez una nueva relación con la poesía (Mora 2002). Es sin embargo el emblemático «Otro romanticismo» el poema que, quizás con el lejano recuerdo de El nuevo romanticismo, de José Díaz Fernández (no olvidemos que la «nueva» sentimentalidad machadiana se transformó en la «otra» sentimentalidad), sintetiza la incomunicación y el frío que acaban atenazando a los amantes: «Será que llevaremos inevitablemente / un lenguaje podrido que amarga el paladar» (Egea 20II: 309). La última sección se halla ocupada en su totalidad por el largo poema reflexivo «Paseo de los tristes». Una suerte de flâneur granadino (Romano 20I2: 122) articula en él con maestría historia individual e historia colectiva, no sin pronosticar «que ha de perderse un día para siempre / este tiempo burgués del exterminio / que, ahora, / enseña su esplendor envejecido / en las ojeras grises de un alba sin amor» (Egea 20II: 324). 
Tan íntimos e históricos como este poema de Egea son los que García Montero incluye en Tristia con los títulos de «Los automóviles», «El envés de la trama» o «I966», mientras que otros del mismo libro tratan ya de elaborar una sentimentalidad amorosa otra. Me refiero a «El lugar del crimen», «Canción de aniversario» (como el título de Gil de Biedma), «Ars amandi» (como el de Ovidio) o "Aventura en la ciudad cerrada», con el inevitable eco de Lorca: «Ven, / te ofreceré Granada, amor, / llena de muerte / si aceptas el infierno con mi mano» (García Montero 20I5: 59). No es en modo alguno casual que, por este camino, El jardín extranjero se inicie con cuatro citas pertenecientes a Gil de Biedma, Salvador, Egea y Juan Carlos Rodríguez («La literatura no ha existido siempre», reza la de este último). Hay en este libro no menos mítico una serie de poemas que se construyen sobre una clara definición histórica de la intimidad, a partir de los orígenes familiares, sentimentales y sociales, como «Paseo marítimo», «Para ponernos nombre», «Como cada mañana» (un poema que vuelve a recordar el albertiano «Colegio (S. J.)»), «Para ser leído muchos años después» y sobre todo la citada «Sonata triste para la luna de Granada», que también acaba con una imagen revolucionaria, la de la marea inundando la ciudad «entre la nube abierta de todos los suburbios» y subiendo hasta Sierra Nevada (88). «Sus ocho nombres» es ya desde el título un homenaje a Alberti (Los ocho nombres de Picasso), concretamente al Alberti comprometido (el poema alude a la Revolución de Octubre y a la proclamación de la Segunda República), el mismo al que La otra sentimentalidad homenajeó en El manifiesto albertista (I982) y el mismo a quien estos poetas nombraron «capitán imprescindible de nuestros ejércitos» al frente de la antología (otro guiño a la Revolución de Octubre) I9I7 versos (Díaz de Castro 2003: I4-I5; Iravedra 2007: 22; Alonso Valero 20IO: 20I; Martín Gijón, 20I7: 229; Lanz 20I8: I40). El último poema del libro, "A Federico, con unas violetas», que no oculta su deuda con el que Cernuda dedica a Larra, se refiere asimismo a la Revolución Rusa incorporando un guiño al Lorca de «I9Io (Intermedio)», de Poeta en Nueva York: «Aquellos ojos nuestros / esperan ser tendidos / sobre mil novecientos diecisiete / corazones en sitio» (García Montero 2015: IIO).

Los poemas de Diario cómplice (I987), salvo el inicial «Invitación» y el final «Invitación al regreso», no tienen título y acuden a la numeración romana. Las dos grandes secciones en que se reparten, «Libro I» y «Libro II», están articuladas por el gozne de los «Fragmentos recogidos en un epistolario». Los términos «diario» y «epistolario» dan cuenta de esa literatura del yo, de la privacidad, que fue a la postre irrenunciable para estos poetas, quienes trataron de configurarla de otro modo, en principio contrario a la «disciplina burguesa de la vida». Aquí, en la conjugación de intimidad e historia, radicaba -ya se dijo más arriba- el verdadero compromiso de la poesía, su potencial para la lucha ideológica. Sin embargo, García Montero también 
llegó a manejar los tonos habituales del compromiso civil en los poemas recogidos en el volumen En pie de paz (1985). Pensemos en el poema así titulado, donde se llama a las palabras «antiguas camaradas del mundo» (García Montero 2015: 8I4), o en títulos reveladores por sí mismos como «Canción por la paz y el desarme», «Consejo para ciudadanos pacifistas», «Himno» o «Uno de mayo", que se viste con ritmo de tango para cantar la libertad, si bien otros títulos de este conjunto, como «Desordenadamente» $\mathrm{y}$ «Balada o epigrama», rompen de modo ingenioso con la instrucción macrolingüística de expectativas (Besa Camprubí 2002: 35I) que de entrada suponen para el lector, aunque quizás no tanto si este nunca se olvida de esa miscelánea engagée a la que pertenecen.

Otro libro de los primeros años ochenta, Rimado de ciudad (198I), respondía al del Canciller López de Ayala señalando la importancia que para la nueva poesía cobraban la experiencia de lo urbano (la sentimentalización de la ciudad) y el conocimiento de la tradición. El autorretrato «Espejo, dime», donde inevitablemente asoma Granada -«Esta ciudad ambigua me ha educado en el arte / de pasar mucho tiempo bajo la misma luna» (García Montero 2015: 849)- es un buen ejemplo de lo primero. En cuanto a lo segundo, la forma clásica del soneto recoge las experiencias de un personaje de suburbio a lo largo de la sección titulada «El aguilucho». La célebre «Égloga de los dos rascacielos» es elocuente, desde su mismo título, de ese intento de mostrar el cambio histórico de los sentimientos (los dos se enamoran de una camarera) sin renunciar a la lección actualizada de los clásicos, como también ocurre con «Coplas a la muerte de su colega», algunos de cuyos versos nos devuelven, con su desenfado aparente, a esa otra concepción del mundo y a ese otro pensamiento que asistieron la poética ideológica (Puertas Moya 1988) - ¿pero qué poética no lo es?-de aquellos jóvenes granadinos: «Nuestras vidas son los sobres / que nos dan por trabajar, / que es el morir; / allí van todos los pobres / para dejarse explotar / y plusvalir; / allí los grandes caudales / nos engañan con halagos, / y los chicos, / que explotando son iguales / las suspensiones de pagos / y los ricos» (García Montero 2015: 876).

\section{Bibliografía}

Alonso Valero, Encarna (2010), «La otra sentimentalidad: poética e ideología», en Entre l'ancien et le nouveau: le socle et la lézarde (Espagne XVIII ${ }^{e}-X X^{e}$ ), eds. Françoise Étienvre y Serge Salaün, París, CREC/Université de la Sorbonne Nouvelle, pp. 189-223.

Aparicio Durán, Pablo (20I6), «La otra sentimentalidad (O el sí a la historia desde la poesía)», en Palabra heredada en el tiempo. Tendencias y estéticas en la poesía española contemporánea (1980-2015), coord. Remedios Sánchez García, Madrid, Akal, pp. 27-42. 
Bellón Aguilera, José Luis (2007), «Todo modo: hechos y palabras en la poesía de la experiencia», Bulletin of Hispanic Studies, 84.6, pp. 797-819.

Besa Camprubí, Josep (2002), El títol i el text. Una tipología dels efectes del títol en el text en poesía, Barcelona, Universitat Autònoma de Barcelona.

Carriedo Castro, Pablo (2012), «Poesía, capitalismo y democracia: una aproximación a La otra sentimentalidad», Revista de Crítica Literaria Marxista, 6, pp. 22-34.

- (20I8), «Tentativas sobre La otra sentimentalidad (Poesía y contrato democrático en España, I980-I985)», Nómadas. Revista Crítica de Ciencias Sociales y Jurídicas, 54.I, s.p.

Díaz de Castro, Francisco (2003), La otra sentimentalidad. Estudio y antología, Sevilla, Fundación José Manuel Lara.

Egea, Javier (20II), Poesía completa I, ed. José Luis Alcántara y Juan Antonio Hernández García, prólogo de Manuel Rico, Madrid, Bartleby.

Egea, Javier, Álvaro Salvador y Luis García Montero (1983), La otra sentimentalidad, Granada, Don Quijote.

García, Miguel Ángel (2002), «Literatura e Historia en La otra sentimentalidad (O cómo poner a la poesía en un compromiso)», Ínsula, 671-672, pp. I6-I8.

García Montero, Luis (I989), El jardín extranjero. Poemas de Tristia, Madrid, Hiperión.

- (20I5), Poesía completa (I980-20I5), prólogo de José-Carlos Mainer, Barcelona, Tusquets.

Iravedra, Araceli (2007), “"Nosotros lo llamamos camarada”: notas sobre Alberti y La otra sentimentalidad», Ínsula, 732, pp. 2I-24.

Jauralde Pou, Pablo (200o), «Poesía contemporánea. Teoría», Voz y Letra, $\mathrm{XI} / 2$, pp. I4I-I5O.

Lanz, Juan José (20I8), «La otra sentimentalidad en su contexto, muchos años después», Studia Iberica et Americana, 4, pp. I27-I64.

Martín Gijón, Félix (20I6), “"El revés de un autógrafo”: notas sobre intimidad e historia en Ángel González y La otra sentimentalidad», Prosemas. Revista de Estudios Poéticos, 2, pp. 59-82.

-. (2017), «Un octubre nuevo. Canon, compromiso y I9I7 versos», en El canon del compromiso en la poesía española contemporánea. Antologías y poemas, ed. Miguel Ángel García, Madrid, Visor, pp. 219-243.

Miró, Emilio (I983), «Dos poetas de Granada y La otra sentimentalidad», Ínsula, 443, pp. 6-7.

Mora, Ángeles (2002), «¿Qué es materialismo?», en Javier Egea, Contra la soledad, ed. Pedro Ruiz Pérez, Barcelona, DVD, pp. I6I-I63.

Nancy, Jean-Luc (2004), Résistence de la poésie, Burdeos, William Blake \& Co. Puertas Moya, Francisco Ernesto (I988), «La otra sentimentalidad: poética ideológica para tiempos de crisis», A Distancia, 2, pp. 35-40. 
Rodríguez, Juan Carlos (1999), Dichos y escritos. Sobre La otra sentimentalidad y otros textos fechados de poética, Madrid, Hiperión.

Romano, Marcela (2012), Revoluciones diminutas. La otra sentimentalidad en Álvaro Salvador y Javier Egea, Sevilla, Renacimiento.

Roso, Pedro (1993), La otra sentimentalidad de Luis García Montero, Córdoba, Antorcha de Paja.

Salvador, Álvaro (1978), La mala crianza, Málaga, Librería El Guadalhorce, $2^{\mathrm{a}} \mathrm{ed}$.

-. (1980), Las cortezas del fruto, prólogo de Juan Carlos Rodríguez, Madrid, Ayuso.

—. (1985), El agua de noviembre, Granada, Diputación Provincial, Maillot Amarillo.

-. (1994), «Con la pasión que da el conocimiento. Notas acerca de la llamada Otra sentimentalidad», Zurgai, diciembre, pp. 44-49.

-. (20I7a), «De La otra sentimentalidad a la nueva banalidad (Pro domo mea)», Pensar Desde Abajo, 6, pp. 24I-250.

-. (2017b), Diario de Firenze, prólogo de Pablo Carriedo Castro, Granada, Colección Carmen del Gallo.

Simonet León, José Antonio (20I7), Hijos de la extrañeza: la ficcionalización del yo en La otra sentimentalidad y la poesía de la experiencia, Universidad de Yale.

Trotski, Leon (1973), Sobre arte y cultura, Madrid, Alianza.

Wahnón, Sultana (2003), «Lírica y ficción: de La otra sentimentalidad a la poesía de la experiencia», en Homenaje a la profesora María Dolores Tortosa Linde, coord. Remedios Morales Raya, Granada, Universidad de Granada, pp. 493-510. 